\title{
Stakeholder Requirements for Commercially Successful Wave Energy Converter Farms
}

\author{
Aurélien Babarit ${ }^{* 1}$, Diana Bull ${ }^{\#}$, Katherine Dykes ${ }^{\circ}$, Robert Malins $^{\#}$, Kim Nielsen ${ }^{\&}$, Ronan Costello ${ }^{\%}$, \\ Jesse Roberts ${ }^{\#}$, Claudio Bittencourt Ferreira ${ }^{\wedge}$, Ben Kennedy ${ }^{\%}$, Jochem Weber ${ }^{\circ}$ \\ "Ecole Centrale de Nantes - CNRS, 1 rue de la Noë, 44300 Nantes, France \\ "Sandia National Laboratories, Albuquerque, New Mexico, USA \\ ${ }^{\circ}$ National Renewable Energy Laboratory, Golden, Colorado, USA \\ ${ }^{\&}$ Ramboll, Denmark \\ ${ }^{\%}$ Wave-Venture, United Kingdom \\ 'DNV GL, United Kingdom
}

\begin{abstract}
In this study, systems engineering techniques are applied to wave energy to identify and specify stakeholders' requirements for a commercially successful wave energy farm. The focus is on the continental scale utility market. Lifecycle stages and stakeholders are identified. Stakeholders' needs across the whole lifecycle of the wave energy farm are analyzed. A list of 33 stakeholder requirements are identified and specified. This list of requirements should serve as components of a technology performance level metric that could be used by investors and funding agencies to make informed decisions when allocating resources. It is hoped that the technology performance level metric will accelerate wave energy conversion technology convergence.
\end{abstract}

KEYWORDS: Wave energy converter, wave energy farm, systems engineering, requirements, technology performance level, technology convergence

\section{INTRODUCTION}

Wave energy converter (WEC) technology development as a whole has not yet delivered the desired commercial maturity or, more importantly, the techno-economic performance needed to penetrate the electric utility marketplace. Both commercial readiness and market viability are required for successful entry into and survival in the energy market.

The ways in which WEC technologies have been developed have been analyzed in [1] and [2]. Technology development progress, technology value, and technology funding have largely been measured, associated with, and driven by technology readiness, measured in technology readiness levels (TRLs). Originating primarily from the space and defense industries, TRLs focus on procedural implementation of technology developments of large and complex engineering projects, where cost is neither mission critical nor a key design driver. The key deficiency with the TRL approach in the context of wave energy conversion is that WEC technology development has been too focused on commercial readiness and not enough on the economic viability required for market entry.

To compensate for this deficiency, technology performance levels (TPLs) have been introduced in [1], and further detailed in [2], as a techno-economic performance assessment metric for WEC technologies. The techno-economic performance assessment metric in [2] provides a means to measure the market viability of different WEC technologies and thus may be used by funding agencies or investors to make informed decisions when allocating resources. The metric was recently used as one of the performance measures in the Wave Energy Prize competition organized by the U.S. Department of Energy [4]. The initial form of the TPL assessment and its corresponding metric were developed based on experience in the wave energy sector, and knowledge of the key performance attributes needed for wave energy converters to be commercially successful [3].

An alternative approach used to identify the components and content of a techno-economic performance metric consists of applying systems engineering techniques. Systems engineering is an

${ }^{1}$ Corresponding author: aurelien.babarit@ec-nantes.fr 
interdisciplinary field of engineering that provides a framework to design and manage complex engineering systems over the entire system lifecycle [5]. It is commonly used in various industries such as aerospace, defense, and oil and gas; the success of the International Space Station is a famous example of its application. The process begins by discovering the core problems that must be resolved to enable a successful solution and, to do this, the framework of systems engineering stays agnostic by not selecting specific design embodiments. It includes identifying stakeholders' needs and requirements with respect to the system. By considering the whole set of stakeholders over the whole system lifecycle, systems engineering provides a holistic list of these stakeholder requirements.

It seems reasonable to argue that market viability (i.e., prospects for commercial success) should be judged based on how well a farm of WECs satisfies stakeholder requirements. To our knowledge, such a list of stakeholder requirements is not available in the context of wave energy. In [6], requirements were formulated in the wave energy conversion context, but only for the mooring system. Even in a more mature industry such as wind energy, only one reference was found dealing just with technical requirements for grid connection of wind energy farms [7]. Therefore, as a joint effort between Ecole Centrale de Nantes, the National Renewable Energy Laboratory (NREL), Sandia National Laboratories, Ramboll, Wave-Venture Ltd., and DNV GL, a list of stakeholder requirements for wave energy farms was developed. This paper reports the outcomes of this work. Guidance from International Standards Organization 15288 [5] as well as IEEE 1233 [8] has been followed.

\section{MISSION STATEMENT FOR A WAVE ENERGY FARM}

The first activity in systems engineering is to precisely identify what is the mission of the product [5]. The product must be considered for a fully mature industry over the entire lifecycle. Therefore, it must be assumed that multiple wave energy farms have been deployed and that there are multiple proven technologies to choose from.

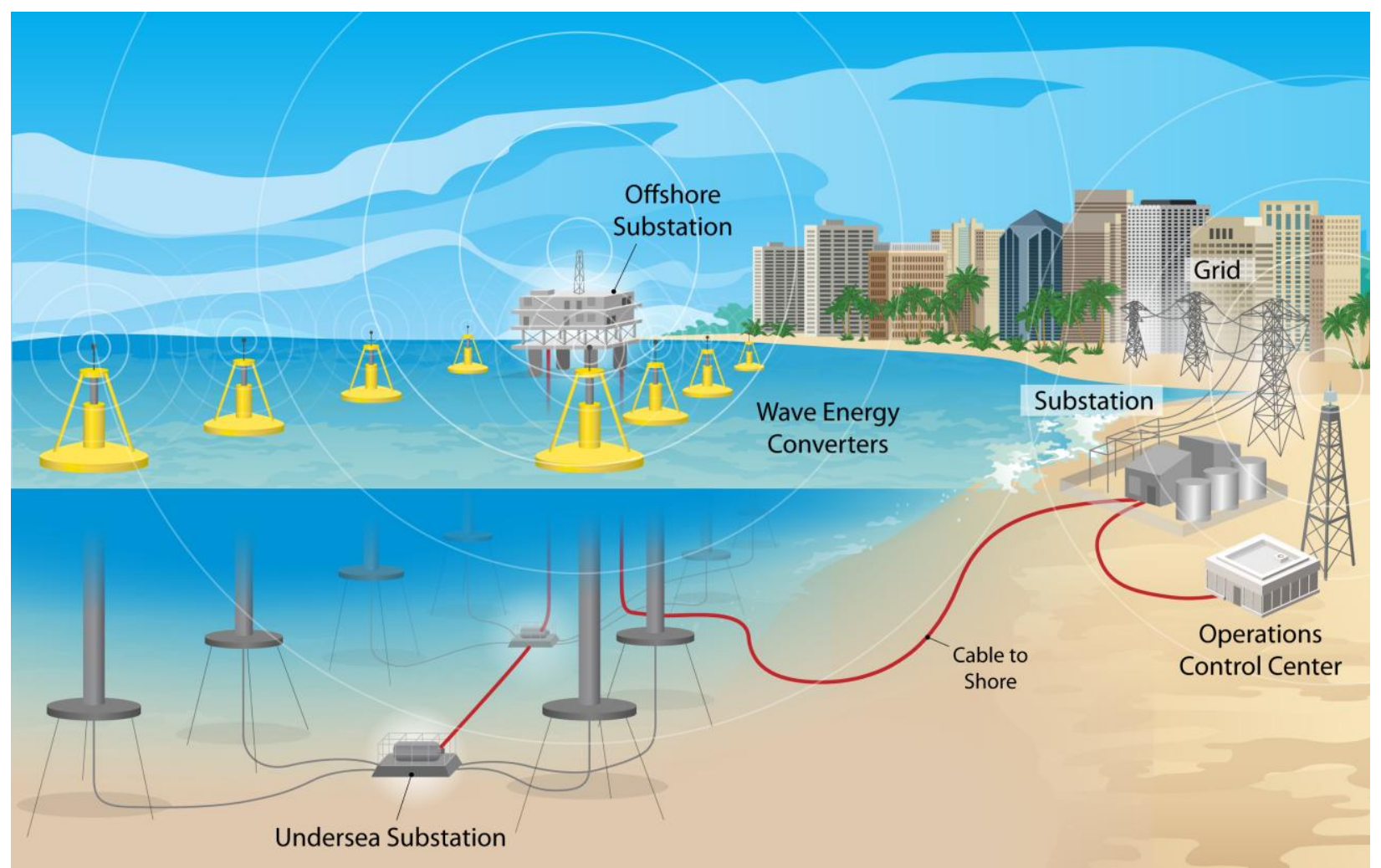

Figure 1. Artist's impression of a wave energy farm (Illustration by Alfred Hicks, NREL)

In systems engineering, distinctions are made between systems, systems-of-systems, subsystems, subsubsystems, and so on [9]. A system is composed of subsystems. A subsystem is composed of subsubsystems. The lowest level in the list of sub-sub-subsystems is called components. A system-of-systems is composed of systems. Systems are characterized by the fact that they are optimized for the specific 
purpose of the system, and the elements of the system (subsystems) are optimized for that same overall purpose. Taking these definitions into account, the wave energy farm is the system. A WEC, which itself is composed of multiple sub-subsystems such as the primary absorber and the power conversion chain, is just one subsystem in the farm. Indeed, for a fully mature wave energy industry, end users of wave energy technologies will operate wave energy farms probably composed of many WEC units. Other necessary subsystems to make a complete wave energy farm include: station-keeping subsystems (mooring subsystems or foundations), grid-connection subsystems (e.g., electrical cables and substations), and communication-and-control subsystems. Figure 1 shows an artist's impression of a WEC farm. According to systems engineering, it should be assumed that there are multiple suppliers available with proven technologies for all the subsystems involved in the wave energy farm, including the WEC units. The work presented here is clearly relevant for WEC technology developers because requirements for a successful WEC technology will follow from the requirements for a successful WEC farm.

The mission statement for the wave energy farm defines what it takes to make the WEC farm successful:

\section{"The wave energy farm converts ocean wave energy to electricity and delivers it to the continental utility market in a competitive and acceptable manner across its lifecycle."}

The continental scale utility system market means a very large electrically interconnected utility grid market. Other markets may be available for WEC farm applications. Indeed, it has been proposed to produce freshwater from seawater and wave energy through desalination (see [10] for example). A niche market (in comparison to the continental utility market) is composed of users connected to micro-grids or not grid-connected users (e.g., oil and gas offshore platforms, isolated science stations or equipment, or island communities). According to [11], wave-powered navigation buoys were commercialized in Japan as early as 1965 . More recently, wave power has been used commercially for propulsion of an ocean sensor platform [12]. In this work, the focus is on the continental scale utility market by choice. It must be acknowledged that stakeholders' requirements may be significantly different for the alternative markets listed above. Identification and specifications of the requirements for these alternative markets are left for future work.

Competitiveness not only includes market-competitive levelized cost of energy (LCOE), but also energy quality, availability of the farm, and investor attractiveness. Competitiveness of a particular wave energy technology in providing electricity to the continental utility market should be judged not only with respect to other wave energy technologies, but also with respect to other renewable energy technologies (i.e., wind turbines or photovoltaics). Indeed, to become economically viable, a wave energy farm that has the cheapest cost of energy of all wave energy farms still needs to be competitive with respect to other renewable energy solutions (at least for certain deployment locations). Note that local public authorities may put in place attractive financial incentives (e.g., feed-in tariffs or tax benefits) for wave energy farms. This may be the case if the wave energy farm provides significant benefits to the society by being a lowcarbon-energy source, or by creating local jobs. This will be discussed further in Section 5.

Acceptability shall be considered across the lifecycle, including environmental acceptability, social acceptability, socio-economic impact and/or benefit, legal and regulatory acceptability, and safety.

\section{LIFECYCLE STAGES OF A WAVE ENERGY FARM}

Systems engineering requires identification of stakeholders at each stage of the lifecycle. Six lifecycle stages have been identified for a wave energy farm. These are depicted in Figure 2. The words "Engineering," "Procurement," "Construction," and "Installation," for the first four lifecycle stages have been used because they are the usual terms within the offshore construction industry. Engineering, procurement, construction, and installation (EPCI) contracts are common forms of contracting arrangements within offshore construction. 


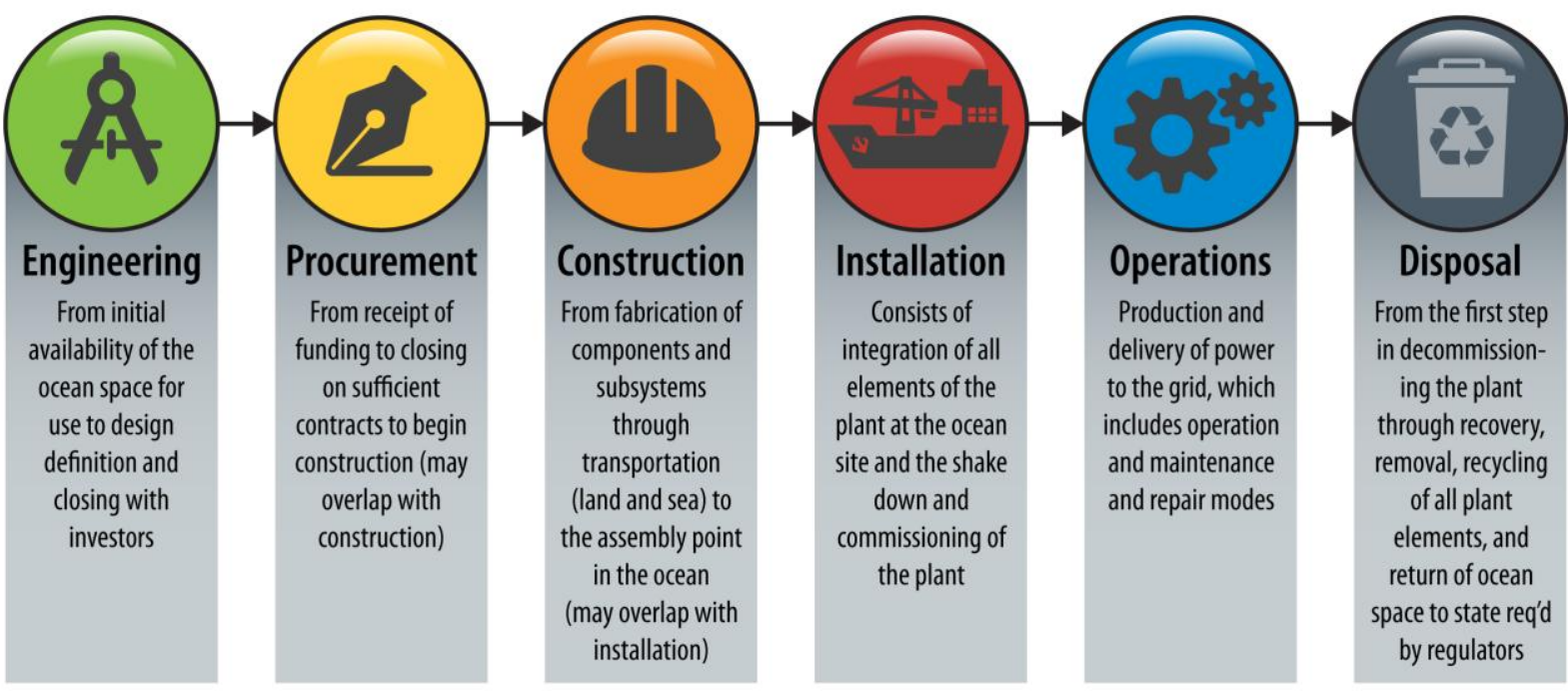

Figure 2. Lifecycle stages of a wave energy farm (Illustration by Alfred Hicks, NREL)

\subsection{Engineering}

Engineering is the first stage of the lifecycle. The objective is to design the wave energy farm, including its technical, legal, and financial aspects. This stage starts with a wave energy farm project developer identifying an opportunity to develop a wave energy farm. It includes identification of available ocean space, estimating the wave energy potential, reviewing for possible environmental impacts, identifying WEC technologies, and potential investors. Activities of the wave energy farm developer in this stage shall aim to:

- Achieve complete wave energy farm technical design and specifications. This includes selecting a suitable, qualified, WEC technology, designing the wave energy farm layout for mooring subsystems, designing the grid connection, establishing procedures and specifications for installation, operation and maintenance, and decommissioning; and developing schedules for the next stages of procurement, construction, and installation. Some of the technical design specifications may be subcontracted to consultants (e.g., ocean engineering firms). It is expected that the final farm design and related procedures will be approved and/or certified by a certifying body.

- Achieve a profitable business model. This may include negotiation of a power purchase agreement (PPA) with a utility company for the electrical power generated by the wave energy farm. Alternatively, the business model may aim to sell the electricity on the wholesale electricity market.

- Obtain all necessary permits and authorizations. This includes both permits for grid connection and use of the ocean space. Permit for use of the ocean space may include securing a lease from a site-use management agency (e.g., the Crown Estate in the United Kingdom). Permits from other regulatory agencies (e.g., environmental or health and safety regulatory agencies) are often also required. Permits from agencies may include conducting environmental studies or monitoring impacts.

- Secure financing from investors and financiers.

- Obtain buy-in from local communities and other users of the area. This may include public meetings and consultations, and developing wave energy farm project-related activities that spur economic development in the area. 


\subsection{Procurement}

Once the wave farm technical design is specified and funding is available, the wave energy farm project can enter the procurement stage. At this point, the wave energy farm developer who carried out the work in the first stage may sell the wave energy farm project to another company that will take charge of the project for the next stages of the lifecycle. The new owner of the wave energy farm may be a construction company or investors for which the wave energy farm is an investment product. In the latter case, construction activities will be subcontracted to a wave energy farm construction company. Such transfers of ownership and responsibilities are common in the wind energy industry. If there is not such a transfer, the initial wave energy farm developer may take the role of the construction company for the next stages of the lifecycle. Alternatively, it may subcontract the construction of the wave energy farm to a wave energy farm construction company, thus retaining ownership.

In all cases, the objective is to contract suppliers for all systems and services that must be provided for the wave energy farm's project until the operations lifecycle stage. Typical systems that may be provided by suppliers are the WEC units, station-keeping systems, grid-connection systems, and communication-and-control systems. Services related to installation of the wave energy farm's systems may be provided by marine contractors. Contracts should specify requirements for quality standards and identify quality-control steps that will be taken during the next lifecycle stage. During this stage, it may be necessary to update the wave energy farm project's schedule and business model. It is also believed that the maintenance service provider should be contracted in this stage of the lifecycle - at least for the first years of operation of the farm. Some of the maintenance activities may be subcontracted to the suppliers that provided the systems in the first place (e.g., subcontracting maintenance of the WEC units to the WEC units' suppliers).

\subsection{Construction}

Once contracts with suppliers of subsystems are in place, construction begins. Suppliers of subsystems may rely on second-tier suppliers for sub-subsystems, components, or materials. Second-tier suppliers may themselves rely on third-tier suppliers for sub-sub-subsystems, components, materials, and so on. Indeed, the supply chain may be a highly complex tree of suppliers. For reliability and availability in the supply chain, the size of the pool of suppliers should increase with decreasing rank of the suppliers. Sub-subsystems or components provided by second-tier and subsequent-tier suppliers should be commercial off-the-shelf products.

In this work, the analysis of the construction lifecycle is focused on the manufacturing and assembly of first-tier subsystems suppliers and/or the wave energy farm construction company. In addition, the construction stage may include activities such as land transportation and storage of subsystems and/or sub-subsystems, land assembly of subsystems and/or sub-subsystems, ocean transportation and storage of subsystems and/or sub-subsystems, ocean assembly of subsystems, quality control, and functionality testing. Functionality testing and quality control are central to this lifecycle stage because these aspects are key to reducing risk and attracting investors. These activities may happen in any order and with possible repeats. Second-tier suppliers may be required to provide services related to land and storage transportation, ocean transportation and assembly (ship providers and operators), and ocean storage.

During this lifecycle stage, it may be necessary to update the wave energy farm project's schedule and business model to take into account delays and/or variations in costs. At the end of this stage, the subsystems are ready (including quality control and certification by certifying bodies) and waiting to be transported to the deployment location in the next lifecycle stage.

\subsection{Installation}

The next stage of the lifecycle is installation. The objective is to make the wave energy farm operational. This stage may rely heavily on marine contractors. In turn, they may rely on ship providers and operators. Consultants (e.g., ocean engineering firms) and certifying bodies may also be involved. This stage may include transportation of subsystems from their last storage location to their deployment locations, and their actual deployment. Numerous marine operations may be involved such as towing, 
lifting, unrolling cables, and ocean assembling/connecting of subsystems. Installation is expected to occur over a period of time during which part of the farm may be commissioned and operated.

During commissioning, the functionality of installed subsystems and sub-subsystems will be verified (e.g., the communications, controls, and quality of power). This stage may require active participation of the certifying bodies before the farm can begin to export power to the continental utility system.

During this lifecycle stage, it may again be necessary to update the wave energy farm project's schedule and business model to take into account delays and/or variations in costs.

\subsection{Operations}

The next stage is operations. The objective is to maximize revenue by producing and selling electricity while maintaining the capability of the farm to do so over the whole farm lifetime. The operations stage starts with the first power delivered to the grid. At this point, the company that took charge of the construction and installation of the WEC farm may sell it to another company that will take care of it during operations. The new owner may be a WEC farm operator or investor for which the wave energy farm is an investment product. In the latter case, the WEC farm's operation activities will be subcontracted to a WEC farm operator. Such transfer of ownership and responsibilities is typical in the wind energy industry. If there is not such a transfer, the company that took charge of the project in the previous stages of the lifecycle may take the role of WEC farm operator. Alternatively, it may subcontract the operation of the WEC farm to a WEC farm operator.

During the operations stage, it is likely that the farm will change its operational mode depending on weather conditions and farm health. Operational modes may include an idle mode, a below-rated mode, a rated mode, a survival mode, a partial shutdown mode, and a complete shutdown mode.

- In the idle mode, the WEC farm shall not produce power. However, all subsystems are ready to start producing power as soon as required external conditions are met. Reasons for entering the idle mode may be that sea conditions are below a minimum threshold (the power consumed by the WEC farm would be larger than the produced power), permit-driven obligations relating to the larger environmental conditions (marine life) or other users in the sea space, grid ancillary requests superseding sea conditions, and fatigue concerns.

- In the below-rated mode, the WEC farm is producing power; however, all components, subsubsystems, and subsystems are on average functioning below rated conditions. The aim in this mode is to maximize produced power. Reasons for entering this operational mode are moderate sea conditions.

- In the rated mode, the WEC farm is producing power and at least one of the components, subsubsystems, and subsystems is being used at full capacity. The aim is to maximize power while ensuring that operational limits are not exceeded for components, sub-subsystems, and subsystems through some form of control mechanism. Reasons for entering this operational mode are that sea conditions are optimal or above optimal with no complicating external factors (environmental conditions, other users in the sea space, grid requests).

- In the survival mode, the WEC farm may or may not be producing power, but maximizing power production is not the aim. The aim is to maintain structural and operational integrity until another operational mode can be safely recommenced. The sea conditions are such that it is not possible to make sure that operational limits will not be exceeded for at least one of the components, subsubsystems, and subsystems, which could lead to unacceptable failure. Reasons for entering this operational mode are excessively large or energetic sea conditions or conflicting use of the sea space.

- In the partial shutdown mode, at least one of the WEC farm subsystems is shut down because of failure or maintenance. The rest of the farm is still operating. The aim of this mode is to enable safe access to a failed system for repair or maintenance purposes. It requires that the failed subsystem be de-energized for safe access. The rest of the farm is still operating as close as possible to normal conditions. 
- In the complete shutdown mode, the entire WEC farm is shut down. The WEC farm can be safely accessed since all subsystems are de-energized. The aim is to maintain structural and operational integrity. Reasons for entering this mode include: farm electrical interconnection system maintenance, grid failure, or loss of grid connection.

Note that because WEC devices are diverse and still under development, there is some uncertainty about these modes. For example, in some designs a survival mode might not be necessary (or the survival and rated modes might be one and the same). The exact nature of the partial and complete shutdown modes is particularly uncertain. It is assumed that most WECs shall be able to shutdown electrical output but some may not be able to prevent motion of the primary absorbers.

Activities of the WEC farm operator include controlling the operational mode of the WEC farm according to the status of the WEC farm systems and external factors, and maintaining the WEC farm in operational conditions. It shall include performing planned and unplanned maintenance activities. The farm is expected to enter the partial or complete shutdown mode during maintenance activities. The maintenance activities may be subcontracted to a maintenance service provider. Spare parts may be provided by WEC farm subsystems suppliers (including the supplier of the WEC units). Consultants (ocean engineering firms) and certifying bodies may be involved by providing services in this stage of the lifecycle.

Of course, activities of the WEC farm operator also include selling the electricity. Electricity may be sold to a utility company through a PPA or on the wholesale electricity market. In both cases, the WEC farm operator shall provide 20-minutes to day-ahead forecasts of the power production to its customers. Weather forecasts may be provided by consultants. Upon request from the grid operator, the WEC farm may also provide ancillary services to the grid.

The operations lifecycle stage ends at the end of the lifetime of the WEC farm.

\subsection{Disposal}

Eventually, the WEC farm operator shall dispose of the WEC farm. This stage includes uninstalling and decommissioning the WEC farm so that the deployment site is cleaned as required in permits and regulations. If permits and regulations allow, parts of the WEC farm or the WEC devices may be scuttled in order to create artificial reefs and additional marine habitat. Marine contractors and recycling firms may be subcontracted. Recycling of parts of the WEC farm may generate complementary revenues in this last stage of the lifecycle. Nonrecyclable parts shall be stored and destroyed, at a cost.

\section{STAKEHOLDERS' LIST}

With the mission statement and the lifecycle stages identified, systems engineering requires listing all stakeholders that interact with the wave energy farm. Stakeholders and their interaction with the WEC farm were discussed briefly in the stages of the lifecycle (see Section 3). Twenty-six stakeholders have been identified. They are shown in Figure 3 along with when they have an active role in the WEC farm lifecycle; they are grouped into four categories.

In the middle are the WEC farm core stakeholders. They are the WEC farm project developer, the WEC farm's owner, the WEC farm construction company, and the WEC farm operator. Note that the WEC farm's owner and the WEC farm construction company-or the WEC farm's owner and the WEC farm operator - may be one and the same stakeholder. The core stakeholders actually run the WEC farm project from its inception to its end. The WEC farm is their key concern because their business model, reputation, and future work depend on its success. The major difference with all the other stakeholders is their requirement to evaluate the farm at the system level - to understand the integration of all of the stakeholders' needs. 


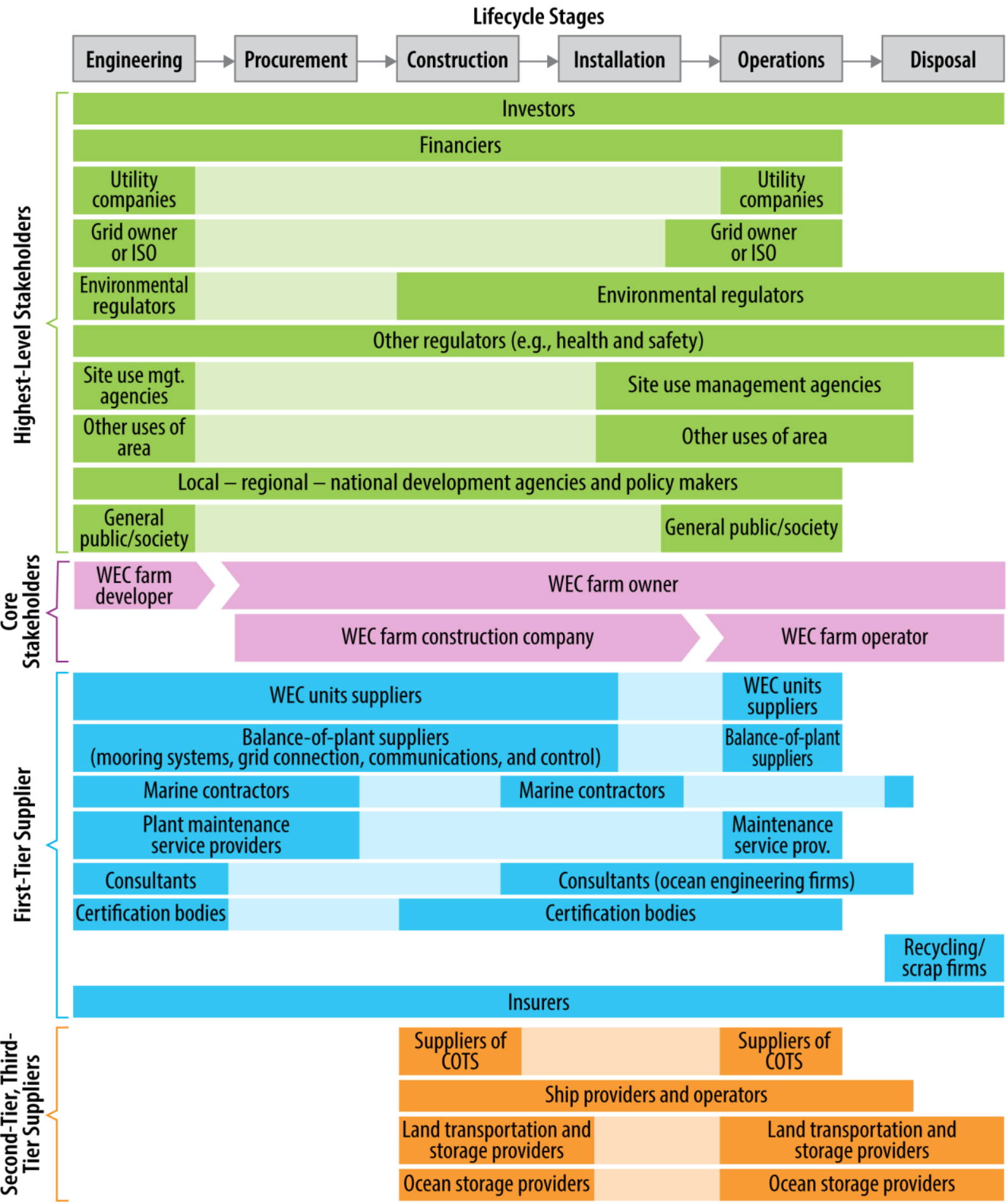

Figure 3. Stakeholders interacting with the WEC farm over the WEC farm lifecycle (Illustration by Alfred Hicks, NREL)

Immediately below the WEC farm core stakeholders are the WEC farm first-tier suppliers. These stakeholders have direct interaction with the WEC farm core stakeholders by providing major services or subsystems required to build the WEC farm (e.g., WEC units or marine operations). The supplied services or subsystems shall satisfy the specifications issued by the WEC farm core stakeholders in terms of technical characteristics, and also with respect to costs. Recalling that a fully mature wave energy industry is to be assumed when applying systems engineering, the WEC farm project is important to the 
WEC farm first-tier suppliers, but it may not be as critical as it is for the WEC farm core stakeholders. Indeed, the WEC farm core stakeholders may be one customer among many, like for wind turbine manufacturers in the wind energy industry. Depending on the number of customers and number of suppliers, the bargaining power may be higher either for the WEC farm core stakeholders or for the firsttier suppliers. Bargaining power may also vary depending on the supplied subsystems or services, and on other external factors such as the demand in other industries. In the early days of an eventually commercial wave energy industry, it may be expected that the bargaining power will be on the side of the WEC farm core stakeholders with respect to WEC unit suppliers, whereas it may be the other way around for other suppliers. This may be expected to shift as the industry develops.

Below the first-tier suppliers are lower-tier suppliers. They don't interact directly with the WEC farm core stakeholders. They are suppliers to the WEC farm first-tier suppliers. There are expected to be large numbers of them, competing in a large market, likely to be broader than the wave energy market. The bargaining power may be either with them or with their customers, depending on the size of the farm with respect to their overall market.

On top of the core stakeholders are the highest-level stakeholders. The highest-level stakeholders are defined as those stakeholders who are customers of the WEC farm (e.g., utility companies, but also investors and financiers) or stakeholders that don't have direct economic interest in the WEC farm. The common point among all of these higher-level stakeholders is that they put requirements on the WEC farm project (and thus on the WEC farm core stakeholders) that must be satisfied for the WEC farm to become a reality.

\section{STAKEHOLDERS' REQUIREMENTS}

The roles of the stakeholders in each of the WEC farm lifecycle stages were further analyzed, along with their needs and desires, with respect to the WEC farm. These are reported in Table 1 to Table 4. 
Table 1. Roles and Needs of the Highest-Level Stakeholders and Core Stakeholders

\begin{tabular}{|c|c|c|c|}
\hline & Stakeholder List & Stakeholder's Role & Stakeholder's Needs and Desires \\
\hline \multirow{10}{*}{ 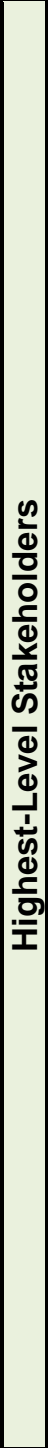 } & Investors & $\begin{array}{l}\text { - Provides funds to the WEC farm project developer and } \\
\text { WEC farm project operator } \\
\text { - Owns shares of the WEC farm project } \\
\text { developer/construction company/operator } \\
\text { - Sets return on investment and profitability }\end{array}$ & $\begin{array}{l}\text { - Market-competitive profitability and return on investment with } \\
\text { minimal project risk } \\
\text { - Well understood and manageable risks for revenues and lifetime } \\
\text { - Maintain reputation to ensure future market share as an } \\
\text { investor-projects should get good press }\end{array}$ \\
\hline & Financiers & $\begin{array}{l}\text { - Provides funds to the WEC farm project developer } \\
\text { - Sets loan rate and collects on the loan } \\
\text { - Makes profit during operations }\end{array}$ & $\begin{array}{l}\text { - Market-competitive interest rate for duration of loan and positive } \\
\text { net present value } \\
\text { - Well understood and manageable risks for revenues and lifetime }\end{array}$ \\
\hline & Utility companies & $\begin{array}{l}\text { - Buys the generated electricity on the wholesale } \\
\text { electricity market or through power purchase } \\
\text { agreements } \\
\text { - Sells the generated electricity to customers }\end{array}$ & $\begin{array}{l}\text { - Wholesale market competitive electricity } \\
\text { - Reliable electricity for electricity market operations including } \\
\text { good timing between the load peak and generation output } \\
\text { particularly on a seasonal basis }\end{array}$ \\
\hline & $\begin{array}{l}\text { Grid owner and } \\
\text { operator or } \\
\text { independent system } \\
\text { operator }\end{array}$ & $\begin{array}{l}\text { - Sets requirements for interfacing to the grid } \\
\text { - Transports the generated electricity from the WEC farm } \\
\text { point of connection to consumers }\end{array}$ & $\begin{array}{l}\text { Reliable electricity for grid operations including predictable } \\
\text { generation for efficient dispatch and demand matching }\end{array}$ \\
\hline & $\begin{array}{l}\text { Environmental } \\
\text { regulators }\end{array}$ & $\begin{array}{l}\text { - Reviews project environmental impact } \\
\text { - Grants authorization and approves farm configuration } \\
\text { for avoiding environmental impacts } \\
\text { - Prosecutes violations of environmental laws } \\
\end{array}$ & - Regulatory requirements are met for environmental impact \\
\hline & Other regulators & $\begin{array}{l}\text { - Reviews project and farm for compliance with other } \\
\text { regulations (e.g., health, safety, working conditions) }\end{array}$ & - Other regulatory requirements are met (e.g., health and safety) \\
\hline & $\begin{array}{l}\text { Site use management } \\
\text { agency }\end{array}$ & $\begin{array}{l}\text { - Reviews project use of ocean space } \\
\text { - Provides the lease or authorization for the ocean space }\end{array}$ & $\begin{array}{l}\text { - Regulatory requirements are met for site use } \\
\text { - High socio-economic benefit of ocean space use }\end{array}$ \\
\hline & Other users of the area & $\begin{array}{l}\text { - Lobbies for or against the WEC farm based on how it } \\
\text { impacts their lifestyle and/or livelihood }\end{array}$ & $\begin{array}{l}\text { - Acceptable modification of livelihood, acceptable impact on } \\
\text { recreational use of ocean area, acceptable impact to social } \\
\text { perspectives on the ocean area }\end{array}$ \\
\hline & $\begin{array}{c}\text { Economic } \\
\text { development agencies } \\
\text { and policymakers }\end{array}$ & $\begin{array}{l}\text { - Facilitates the WEC farm project development } \\
\text { (incentives, subsidies, revenue bonds, guarantee loans) }\end{array}$ & $\begin{array}{l}\text { - Positive societal impact in their area, such as tax revenue, jobs } \\
\text { generation, tourism, and reduction of emissions } \\
\text { - Acceptable environmental impacts }\end{array}$ \\
\hline & $\begin{array}{l}\text { General public and } \\
\text { society }\end{array}$ & $\begin{array}{l}\text { - Lobbies for or against the WEC farm based on its } \\
\text { impacts to society } \\
\text { - Buys the electricity generated by the WEC farm from the } \\
\text { utility companies and consumes it }\end{array}$ & $\begin{array}{l}\text { - Positive impact for society, as listed above } \\
\text { - Carbon free market-competitive electricity } \\
\text { - Acceptable environmental impacts }\end{array}$ \\
\hline
\end{tabular}




\section{Table 2. Roles and Needs of the Highest-Level Stakeholders and Core Stakeholders}

\begin{tabular}{|c|c|c|c|}
\hline & Stakeholder List & Stakeholder's Role & Stakeholder's Needs and Desires \\
\hline \multirow{4}{*}{ 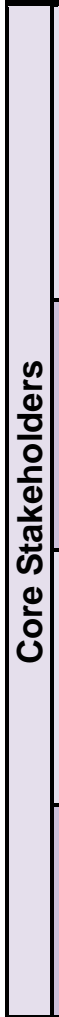 } & $\begin{array}{l}\text { WEC farm project } \\
\text { developer }\end{array}$ & $\begin{array}{l}\text { - Develops WEC farm design and business model } \\
\text { - Finds funding from investors and financiers } \\
\text { - Obtains all necessary permits to construct, install, and } \\
\text { operate the farm } \\
\text { - Ensures the WECs will be certifiable and eligible for } \\
\text { insurance } \\
\text { - Sells WEC farm to next owner }\end{array}$ & $\begin{array}{l}\text { - WEC farm less costly than available sales price } \\
\text { - Maintain good reputation to ensure future market share } \\
\text { - Steady sales to maintain business } \\
\text { - Easy permitting with no operating restrictions } \\
\text { - A steady business and project development volume, without } \\
\text { stops and starts }\end{array}$ \\
\hline & WEC farm's owner & $\begin{array}{l}\text { - Buys the WEC farm project from WEC farm project } \\
\text { developer or previous owner } \\
\text { - Subcontracts WEC farm construction to a WEC farm } \\
\text { construction company } \\
\text { - Subcontracts WEC farm operations to a WEC farm } \\
\text { operator }\end{array}$ & $\begin{array}{l}\text { - Generated electricity less costly than available sales price } \\
\text { - Cost takes into account all cost sources (capital expenditures } \\
\text { (CapEx), operational expenditures (OpEx), financial costs, and } \\
\text { decommissioning costs) and lifetime } \\
\text { - No operating restrictions or monitoring requirements }\end{array}$ \\
\hline & $\begin{array}{c}\text { WEC farm construction } \\
\text { company }\end{array}$ & $\begin{array}{l}\text { - Contracts suppliers } \\
\text { - Manages farm construction and installation } \\
\text { - Coordinates the installation sequence and } \\
\text { commissioning sequence }\end{array}$ & $\begin{array}{l}\text { - WEC farm construction less costly than available sales price } \\
\text { - Maintain good reputation to ensure future market share } \\
\text { - Well understood and manageable risks during construction and } \\
\text { installation } \\
\text { - Safe WEC farm to build and install } \\
\text { - Steady sales to maintain business }\end{array}$ \\
\hline & WEC farm operator & $\begin{array}{l}\text { - Operates the farm } \\
\text { - Sells electricity on the wholesale electricity market to } \\
\text { utility companies } \\
\text { - Maintains the farm in operational conditions } \\
\text { - Performs decommissioning operations } \\
\end{array}$ & $\begin{array}{l}\text { - WEC farm operations less costly than available sales price } \\
\text { - Well-understood and manageable risks for revenues and } \\
\text { lifetime } \\
\text { - Safe WEC farm to operate and maintain }\end{array}$ \\
\hline
\end{tabular}


Table 3. Roles and Needs of the First-Tier Suppliers of the WEC Farm

\begin{tabular}{|c|c|c|c|}
\hline & Stakeholder List & Rationale and/or Role Notes & Stakeholder's Needs and Desires \\
\hline \multirow{8}{*}{ 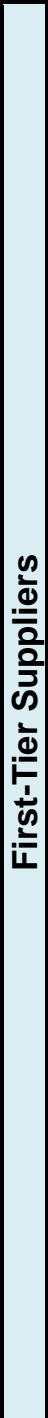 } & WEC unit suppliers & $\begin{array}{l}\text { - Provides certified WEC units and design specifications } \\
\text { for WEC installation and balance of farm, grid } \\
\text { connection, operation, maintenance, and } \\
\text { decommissioning } \\
\text { - Provides spare parts } \\
\text { - Provides a warranty on the WEC units sold and power } \\
\text { production capability in specified sea state }\end{array}$ & $\begin{array}{l}\text { - WEC unit less costly than available sales price } \\
\text { - Steady sales to maintain business } \\
\text { - No warranty claims (device compatible with site environment) }\end{array}$ \\
\hline & $\begin{array}{l}\text { Balance of farm } \\
\text { suppliers (e.g., } \\
\text { mooring subsystems } \\
\text { suppliers, grid } \\
\text { connection suppliers, } \\
\text { communication and } \\
\text { control suppliers) } \\
\end{array}$ & $\begin{array}{l}\text { - Provides general purpose subsystems and sub- } \\
\text { subsystems needed to create the rest of the farm (e.g., } \\
\text { cables, mooring lines, instrumentation, and equipment } \\
\text { for communication and controls) } \\
\text { - Provides spare parts } \\
\text { - Provides a warranty on products sold }\end{array}$ & $\begin{array}{l}\text { - Supplied subsystems and sub-subsystems less costly than } \\
\text { available sales price } \\
\text { - Steady sales to maintain business } \\
\text { - No warranty claims }\end{array}$ \\
\hline & Marine contractors & $\begin{array}{l}\text { - Provides necessary services for ocean assembly and } \\
\text { installation of the WEC farm } \\
\text { - Guarantees installation meets specifications }\end{array}$ & $\begin{array}{l}\text { - Integration and installation operations less costly than available } \\
\text { sales price } \\
\text { - Safe access to necessary facilities and equipment } \\
\text { - Steady sales to maintain business }\end{array}$ \\
\hline & $\begin{array}{l}\text { WEC farm } \\
\text { maintenance service } \\
\text { providers }\end{array}$ & $\begin{array}{l}\text { - Performs maintenance operations on the farm } \\
\text { - Deals with stock of spare parts } \\
\text { - May return major elements to vendors for maintenance } \\
\text { - Guarantees minimum WEC availability }\end{array}$ & $\begin{array}{l}\text { - Maintenance operations less costly than available sales price } \\
\text { - Safe maintenance operations } \\
\text { - Steady sales to maintain business }\end{array}$ \\
\hline & $\begin{array}{l}\text { Consultants (ocean } \\
\text { engineering firms) }\end{array}$ & $\begin{array}{l}\text { - Provides information on meteorological ocean } \\
\text { conditions for WEC farm design, installation, and } \\
\text { operation }\end{array}$ & $\begin{array}{l}\text { - Available prediction methodologies and measurement data for } \\
\text { determining meteorological and ocean forecasts }\end{array}$ \\
\hline & Certifying bodies & $\begin{array}{l}\text { - Reviews and certifies design and procedures according } \\
\text { to existing standards and guidelines }\end{array}$ & $\begin{array}{l}\text { - Applicable standards and guidelines for WEC farm design and } \\
\text { operating procedures }\end{array}$ \\
\hline & $\begin{array}{l}\text { Recycling and scrap } \\
\text { firms }\end{array}$ & $\begin{array}{l}\text { - Destroys, recycles, and disposes of the remains of the } \\
\text { WEC farm }\end{array}$ & - Operations less costly than available sales price \\
\hline & Insurers & $\begin{array}{l}\text { - Provides insurance, including WEC damage to third- } \\
\text { party equipment, accidental damage to WEC, insurance } \\
\text { against storm damage, and "construction all risk" } \\
\text { insurance }\end{array}$ & - Well understood and manageable risks for project assets. \\
\hline
\end{tabular}


Table 4. Roles and Needs of the Sublevel Suppliers of the WEC Farm

\begin{tabular}{|c|c|c|c|}
\hline & Stakeholder List & Rationale and/or Role Notes & Stakeholder's Needs and Desires \\
\hline \multirow{4}{*}{ 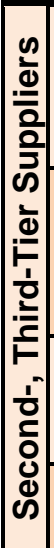 } & $\begin{array}{l}\text { Subsuppliers (second- } \\
\text { and third-tier suppliers } \\
\text { of specialized and off- } \\
\text { the-shelf items) }\end{array}$ & $\begin{array}{l}\text { - Provides critical materials, components, sub-sub- } \\
\text { subsystems, processes that the first-tier suppliers need } \\
\text { - Provides spare parts }\end{array}$ & $\begin{array}{l}\text { - Supplied materials, components, processes, sub-sub- } \\
\text { subsystems less costly than available sales price } \\
\text { - Steady, dependable business volume }\end{array}$ \\
\hline & $\begin{array}{l}\text { Ship providers, } \\
\text { operators, and ocean } \\
\text { storage suppliers }\end{array}$ & $\begin{array}{l}\text { - Provides ocean transportation (e.g., towing) and lifting } \\
\text { services at sea } \\
\text { - Provides storage at sea for WEC farm components, } \\
\text { sub-subsystems, and subsystems }\end{array}$ & $\begin{array}{l}\text { - Provided services less costly than available sales price } \\
\text { - Steady, dependable use of equipment with low idle time }\end{array}$ \\
\hline & $\begin{array}{l}\text { Land transportation } \\
\text { and storage suppliers }\end{array}$ & $\begin{array}{l}\text { - Provides land transportation services } \\
\text { - Provides land storage for WEC farm components, } \\
\text { subsystems, and systems }\end{array}$ & $\begin{array}{l}\text { - Provided services less costly than available sales price } \\
\text { - Steady, dependable business volume }\end{array}$ \\
\hline & $\begin{array}{l}\text { Ocean storage } \\
\text { suppliers }\end{array}$ & $\begin{array}{l}\text { - Provides ocean storage services for WEC farm } \\
\text { subsystems }\end{array}$ & $\begin{array}{l}\text { - Provided services less costly than available sales price } \\
\text { - Steady, dependable business volume }\end{array}$ \\
\hline
\end{tabular}


The needs of individual stakeholders have been further condensed into a distilled list of stakeholders' requirements that ensure the WEC farm will satisfy all the needs of each stakeholder. This list is presented and discussed in the following subsections.

\subsection{Cost of energy}

All of the stakeholders in the WEC farm supply chain (owners; first-, second-, and third-tier suppliers) need to make money. At a minimum, this means the supplied materials, components, subsubsystems, subsystems, or provided services are less costly than available sales prices. Low costs are driven by:

- Simple design

- Ease of manufacturing

- Ease of transportation

- Installation

- Maintenance

- Reliability

- Durability

- Steady, dependable product sales.

High available sales prices are driven by high quality (lifecycle performance) of supplied materials, components, sub-subsystems, subsystems, or provided services in terms of energy conversion efficiency and availability (reliability and durability).

The needs of the last link in the supply chain - the WEC farm operator-are believed to be particularly critical. The product sold by this stakeholder is the electricity produced by the WEC farm. Available sales prices are set by utility companies that want market-competitive cost of energy. Note that market prices may vary among energy sources in some countries. There may be feed-in tariffs for wave energy or renewable energy sources, or there may be renewable energy certificates or renewable obligations. Some countries may also require that a certain percentage of the energy portfolio of utility companies is provided by renewable energy. Cost of energy shall take into account:

- Capital expenditures (CapEx)

- Operational expenditures (OpEx)

- Financial and insurance costs

- Disposal costs

- Energy production (including high availability, and predictable output)

- Lifetime.

Regarding cost of energy, a first set of requirements is specified:

\section{SR1. Have market-competitive cost of energy}

Electricity from the wave energy farm may be sold on the day-ahead wholesale electricity market or through a PPA. In both cases, the sales price of the produced electricity shall be competitive with other energy sources. However, note that market price may vary among energy sources in some countries. There may be feed-in tariffs, renewable energy certificates, or renewable obligations for wave energy or renewable energy sources. Some countries may also require that a certain percentage of the energy portfolio of utility companies is from renewable energy sources. 
The subtier stakeholder requirements below identify the variables in the LCOE equation. The LCOE of the wave energy farm is needed to determine if the project will have a marketcompetitive cost of energy.

SR1.1 Have as low CapEx as possible.

CapEx includes all costs that occur in the development and construction of a WEC farm until it starts producing electricity. It should also include decommissioning costs. The WEC farm should have as low a CapEx as possible. Drivers of CapEx are design, manufacturability, transportability, and installability. It includes costs related to grid connection.

\section{SR1.1.1 Be a low cost design}

A WEC farm should have an elegant design and as few components/subsubsystems as possible with many suppliers for the components and subsubsystems. It should minimize the required material quantities and it should make use of low-cost material types. It may maximize recycling opportunities to provide additional revenues at the end of the WEC farm's lifetime.

\section{SR1.1.2 Be manufacturable at low cost}

The WEC farm should be easy and quick to mass produce. It should minimize the need for specialized tools and equipment, highly qualified workers, and dedicated or specialized infrastructure for manufacturing, assembly, and storage. The WEC farm may provide cost-offsetting by performing more than one service.

\section{SR1.1.3 Be inexpensive to transport (excluding install)}

WEC farm components, sub-subsystems, and subsystems should be built close to the manufacturing and/or deployment site to minimize shipping and transportation costs. Alternatively, the sub-subsystems and subsystems should be of a size and modularity for which standard transportation is possible. They should be transportable in any weather conditions.

\section{SR1.1.4 Be inexpensive to install}

WEC farm subsystems should be installable in most weather conditions, require minimal time to complete the installation, use readily available vessels, and minimize the need for skilled workers.

\section{SR1.2 Have as low OpEx as possible}

OpEx includes all costs necessary to operate and maintain the WEC farm over its entire service life. The WEC farm should have as low OpEx as possible. Drivers of OpEx are reliability (unplanned maintenance) and durability (planned maintenance).

\section{SR1.2.1 Be reliable (to avoid costly unplanned maintenance)}

The WEC farm should be highly reliable to avoid costly unplanned maintenance. High reliability is achieved with proven high-quality components, by minimizing the number of parts or components subject to well-known failure modes (fatigue, wear, abrasion, corrosion, chemical attack, thermal overload, clogging, and photolysis), and by avoiding impulsive loads (end-stops, shock loading, and snap loads). Cost of repair for subsystems that are likely to require frequent unplanned maintenance should be low. Costs could include replacement parts, transportation to and from the site of repair, fees incurred as a result of wait times for weather windows, and 
fees for trained workers. Costs do not include lost revenue as a result of downtime.

\section{SR1.2.2 Be durable over the lifetime of the plant (to avoid costly planned maintenance)}

The WEC farm should be highly durable to avoid costly planned maintenance. The WEC farm is ideally made of high-durability (long lifetime) components. The number of parts and components subject to wear, abrasion, and erosion is small. Ideally, the durability of a farm's components, sub-subsystems, and subsystems is the same as the lifetime of the farm. Cost of servicing for subsystems that require planned maintenance should be low. Costs could include: replacement parts, transportation to and from the site, fees incurred as a result of wait times for weather windows, and fees for trained workers. Costs do not include lost revenue as a result of downtime.

SR1.3 Be able to generate large amounts of electricity from wave energy

The amount of electricity generation is an essential driver to the value of the WEC farm (i.e., the sales price of the WEC farm as a product). Large amounts of electricity generation enable a high energy yield and hence high revenues.

\section{SR1.3.1 Absorb large amounts of wave energy}

The WEC farm should absorb a high percentage of the wave energy that passes through the farm. This implies that the farm can absorb energy across a wide range of frequencies, heights, and wave directions. It should be minimally affected by tide, current, and wind. Negative array interference interactions should be minimal. Availability will not be covered here because it is taken into account in requirement $\mathrm{S} 0$.

\section{SR1.3.2 Have high-conversion efficiency of extracted energy to electrical energy}

The WEC farm device power conversion chain and electrical collection system should have a small number of conversion steps and each conversion step should be highly efficient. Availability will not be covered here because it is taken into account in requirement $\mathrm{S} 0$.

SR1.4 Have high availability

In this paper, we define availability as the ratio of the average annual power of the farm to the theoretical maximum power capacity. We define the WEC farm rated power as the maximum power that the farm can deliver to the utility system at the point of connection to the utility grid. Thus, rated power is determined by the power carrying capability of the interconnection cable from the WEC farm and the substation's power handling capacity. A high availability will enable a high energy output and a dependable output thereby increasing the value of the WEC farms electricity.

\section{SR1.4.1 Be reliable (to avoid lost revenue as a result of dowtime)}

The WEC farm should be highly reliable to avoid downtime as a result of unplanned maintenance. High reliability is achieved with proven high-quality components, by minimizing the number of parts and components subject to well-known failure modes (fatigue, wear, abrasion, corrosion, chemical attack, thermal overload, clogging, and photolysis), and by avoiding impulsive loads (end-stops, shock loading, and snap loads). Duration of repairs for subsystems that may require unplanned maintenance (including wait time between weather windows) should be short. Reliability with respect to availability accounts for the lost revenue as a result of downtime. 

downtime)

The WEC farm should be highly durable to avoid downtime as a result of planned maintenance. The WEC farm is ideally made of high-durability (long lifetime) components, and the number of parts and components subject to wear, abrasion, and erosion is small. Ideally, the durability of a farm's components, sub-subsystems, and subsystems is the same as the lifetime of the farm. Time of servicing for subsystems that require planned maintenance (including wait time between weather windows) should be short. Durability with respect to availability accounts for the lost revenue as a result of downtime.

SR1.5 Have a low financing rate

Financing rate is the cost of the money borrowed from investors and financiers to build and operate the WEC farm. Financing rate is dictated by investors and financiers according to current market climate and reputation of the WEC technology. The reputation of the WEC technology depends on its track record. The WEC farm project controls the financial risk of the technology - the higher the risk, the higher the financing rate.

\section{SR1.6 Have a low insurance rate}

Financial risk may be mitigated with insurance. Insurance may cover the risks that the investors and financiers are not willing to take. To be insurable, these risks shall be well understood and manageable. The criticality of these risks (i.e., the likelihood of these risks and their financial consequences) drive the insurance rate.

\subsection{Risks}

Investors and financiers will dictate a financing rate based on financial risks (i.e., risks that the WEC farm will not deliver the expected financial return). Risk shall be low to attract investors and financiers with large financial capabilities (e.g., pension funds). High-risk projects need specialized investors whose financial capabilities may be limited, thus constraining the size of the WEC farm. Some of the sources of risks may be mitigated through insurance but most are mitigated through the experience of past projects. Of course, insurance costs will depend on the risk's criticality (i.e., the likelihood of the risk and its financial consequences). Thus, overall, the WEC farm shall provide a secure investment opportunity.

Assuming a fully mature industry, WEC farm risks are risks that the farm does not deliver on expectations. As stated before, the concern for investors and financiers is the risk that the farm does not deliver the expected return. For the WEC farm construction company, the risk is that the construction work will take more time and money than initially planned (i.e., CapEx risks). For the WEC farm operator, the risks are that revenues (energy production and availability) are lower than expected, that the OpEx is greater than expected, and that the farm does not survive until the end of its expected lifetime.

The concept of survivability needs to be clarified. Recalling that systems engineering requires assuming a fully mature industry, it shall be assumed that the limit states for the WEC farm design are well defined and understood. It means that the WEC farm design fulfills the relevant design criteria up to the limit states. Limit states shall include (this is a nonexhaustive list):

- Extreme environmental conditions and extreme loads response conditions during operations

- Extreme environmental conditions and loads response during temporary conditions (installation and maintenance)

- Grid failure, grid loss, or grid interruption

- Collisions with other marine users, ships, or marine mammals. 
Failure of a WEC farm's subsystem, sub-subsystem, or component — despite conditions that are below limit states-actually corresponds to a reliability or durability problem. It will impact OpEx and availability of the WEC farm for which requirements have already been formulated.

However, because of the stochastic nature of the WEC farm environment (including other users of the area and the grid), conditions that are beyond limit states, even if unlikely, may happen (e.g., a perfect storm). It may be a great deal of risk for investors, financiers, and the WEC farm's owner because the consequences may be catastrophic. Thus, financial consequences of conditions that are beyond limit states and their probabilities shall be well understood and as low as possible. In this work, survivability is defined as the combination of probabilities and consequences of conditions beyond limit states.

Other risks relating to environmental acceptability and health and safety, both of which are relevant to owners and management of all companies involved because of risks of legal consequences of any incidents are considered separately in Sections 5.4 and 5.6.

This risk discussion leads to the specification of these requirements:

\section{SR2. Provide a secure investment opportunity}

For investors and financiers, it is critical that WEC farm risks are well understood and manageable so investors and financiers know the financial risk (i.e., the risk that the farm will not deliver the expected financial return). The financial risk results from the analysis of the probabilities of the risks and of their financial consequences. Uncertainties on costs (CapEx and OpEx), revenues (energy production and availability), and survivability are the drivers.

SR2.1 Low uncertainty on costs and revenues

Uncertainties and external factors may make CapEx, OpEx, energy production, and availability deviate from expectations even though the WEC farm is operating in conditions that are below limit states.

\section{SR2.1.1 Low uncertainty on OpEx}

OpEx may be greater than expected because of uncertainties in the reliability and/or durability of components and sub-subsystems of the WEC farm. The WEC farm shall be made of proven technologies. Standard deviations and uncertainties on the mean time between failures of the WEC farm's subsystems, sub-subsystems, and technologies may be used to assess the risk on OpEx.

\section{SR2.1.2 Low uncertainty on availability}

Availability may be smaller than expected because of uncertainties in the reliability and/or the durability of components and sub-subsystems. If unplanned maintenance activities are more frequent than expected, the farm availability is less than expected. Availability may also be diminished because waiting time between weather windows for planned and unplanned maintenance is longer than expected.

SR2.1.3 Low uncertainty on energy production

Energy production may be smaller than expected because the resource may be smaller than expected. Energy production estimates are normally made based on the statistically worst year. First power delivery may be delayed because of acceptability issues or delays in construction. This type of uncertainty may be mitigated through insurance or penalties in contracts with suppliers.

SR2.1.4 Low uncertainty on CapEx

CapEx may be greater than expected. It may happen because of an increase in materials and/or component prices; and/or increased manufacturing 
costs/durations; and/or increased transportation and installation costs. The supply chain should be low risk.

SR2.2 Survivable

Because of the stochastic nature of the farm environment (including other users of the area and grid), and uncertainties in the understanding of the response of the farm, conditions beyond limit states may happen. These events may cause damage. The financial consequences (loss of revenues because of downtime, loss of assets, cost of repairs) shall be well understood and as low as possible.

\section{SR2.2.1 Be able to survive extreme loads and responses}

Because of the stochastic nature of the marine environment, weather conditions or operational conditions may lead to extreme loads and responses that exceed ultimate limit states or fatigue limit states design conditions. The probabilities of such events and their financial consequences (repair costs, loss of assets, or loss of production) shall be understood. If relevant, possible cascade failures shall be taken into account.

\section{SR2.2.2 Be able to survive grid failures, grid loss, or grid interruption}

The grid is an external system to the WEC farm. Grid failure is a critical ultimate limit state. As such, the WEC farm design shall be able to cope with it. However, characteristics of grid failure (particularly downtime) may exceed the specifications in the corresponding ultimate limit state. Often loss of the gird is highly correlated with extreme weather events and for that reason WEC ultimate limit states may need to be considered simultaneously with loss of grid events. Technical consequences of such events shall be harmless for the WEC farm and the financial consequences should be minimal.

\section{SR2.2.3 Be able to avoid and survive collisions}

Other marine users, ships, and marine mammals are external systems to the WEC farm. They may collide with one or several subsystems of the farm, resulting in an accidental limit state. It may result in cascade failures. Technical and financial consequences of such events should be low.

SR2.2.4 Be survivable in temporary conditions, including installation (tow-out, if applicable) and maintenance

Because of the stochastic nature of the marine environment, weather or operational conditions may lead to extreme loads and responses that exceed serviceability limit states during temporary conditions. The probabilities of such events and their financial consequences should be understood.

\subsection{Utility grid operations}

In this work, the market for the produced electricity is the continental utility market. For utilities to buy the produced electricity in this market, the WEC farm operator must be able to provide reliable forecasts of energy production with a 20-minute to 24-hour horizon. Energy production forecasts are often still needed even if the electricity is sold to a utility through a PPA.

Moreover, the increase of the share of intermittent renewable energy sources in the energy mix is challenging for grid operators with respect to grid stability and load balancing. This may limit the development of the wave energy industry. Thus, energy production from the WEC farm should have a high capacity factor, as well as energy output that is correlated with the daily and seasonal demand. It may also provide useful ancillary services to the grid, including energy storage automatic generation control as well as voltage and frequency control. Providing these services may be an additional source of revenue for the WEC farm operator and may increase the acceptability of the WEC farm for the grid operator. 
Thus, the following stakeholder requirements have been specified:

\section{SR3. Be reliable for grid operations}

Reliability for grid operations covers several aspects. Energy production from the WEC farm shall be forecastable to enter the day-ahead wholesale electricity market. Moreover, the increase of the share of intermittent renewable energy sources in the energy mix is challenging for grid operators with respect to grid stability and load balancing. This could limit the development of the wave energy industry. Thus, the WEC farm should have a high-capacity factor and produce electricity during periods of higher electricity demand. Moreover, a WEC farm may provide useful ancillary services to the grid. These include energy storage, automatic generation control, and voltage and frequency control.

\section{SR3.1 Be forecastable and have high power quality}

The electricity market requires prediction of energy production in advance to maintain equilibrium with the load; thus, the energy production from the WEC farm should be forecastable. Typical prediction horizons are in the range of 20 minutes to day-ahead.

\section{SR3.2 Have stable annual power production}

Long-term variability is an issue for the grid operator in planning future energy capacities and reserves. Grid operators prefer power sources that can contribute to base load or are available on demand. High-capacity factor, defined as the ratio of the farm output over a year to its potential output if it were operating continuously at full nameplate capacity, characterizes low long-term variability. The WEC farm should have a high-capacity factor and produce power during periods of higher demand.

SR3.3 Be useful to the grid by supplying ancillary services

The integration of intermittent renewable energy sources is challenging for grid operators with respect to grid stability and load balancing. However, WEC farms may provide useful ancillary services to the grid. These include energy storage, automatic generation control, voltage and frequency control, and operational reserves.

\subsection{Acceptability}

A WEC farm shall obtain buy-in and support from the local communities and the general public. Indeed, the deployment of a WEC farm inevitably causes a change in the use of the ocean space at the deployment site that is likely to disrupt the activities of other users of the area. For the general public, the WEC farm may cause increased electricity prices or increased taxes if it is subsidized. To obtain buy-in and support, the WEC farm shall bring benefits to local communities and the general public that largely overcome the negative impacts. Benefits may include electricity from a local, low-carbon-emission energy source, local job creation, and coastal protection. Otherwise, public concerns and actions against the project may seriously delay the project or cause it to fail (even if permits are granted). Benefits for the local communities and the general public may lead local, regional, and national economic development agencies and policymakers to facilitate the WEC farm project development (e.g., incentives, subsidies, revenue bonds, guarantee loans, or tax credits).

Thus, the following stakeholder requirements have been specified:

\section{SR4. Benefit society}

A WEC farm needs to obtain buy-in and support from the local communities and the general public. Like any industrial project, a WEC farm is likely to cause some negative impacts (higher cost of energy, disruption to other activities) that shall be largely overcome by benefits for society (low-carbon-emission energy source, local job creation, or coastal protection). Otherwise, public concerns and actions against the project can seriously delay the project or cause it to fail (even if permits are granted).

SR4.1 Be beneficial to local communities 
The WEC farm shall be beneficial to local communities to obtain buy-in and support from them. Local benefits may include local job creation, increase of local gross domestic product, protection from coastal erosion, increases in the local tax base, or improvement of infrastructure. Local benefits shall largely overcome possible negative impacts (e.g., visual obstruction in the seascape).

\section{SR4.2 Be a low-greenhouse-gas-emission energy source}

The WEC farm needs to be a low-greenhouse-gas-emission energy source over the entire lifecycle. A measure of lifecycle greenhouse-gas emissions is the global warming potential per unit of electrical energy generated. The global warming potential is the ability of a greenhouse gas to trap heat in the atmosphere relative to an equal amount of carbon dioxide, and is dependent upon a full lifecycle assessment.

SR4.3 Be a low-polluting energy source

The WEC farm should not pollute the environment during construction, operation, or disposal. The use of readily available and environmentally inert materials is desired. The entire lifecycle shall be considered.

SR4.4 Have minimal impact on taxpayers and electricity consumers

Electricity consumers are the final users of the generated electricity. They want marketcompetitive electricity in the long term.

SR4.5 Contribute significantly to energy security

Like other renewable energy sources, a WEC farm contributes to energy security. It does not rely on foreign countries for supplying necessary fuel. The contribution to energy security should be significant (i.e., the WEC farm should be a significant share of the energy mix).

\subsection{Permitting}

The WEC farm developer, the WEC farm construction company, and the WEC farm operator all need permits for occupying in the sea space and connecting to the grid. These permits shall be obtained from the appropriate regulators before starting the WEC farm construction. The requirements should consist of assessing and addressing environmental impacts, impacts to other users of the area, and impacts to the electrical grid.

\section{SR5. Be acceptable for permitting and certification}

Permits for occupying the sea space and connecting to the grid shall be obtained by the WEC farm developer before starting construction of the WEC farm. Consequently, the WEC farm shall fulfill all regulatory and permitting requirements. The requirements usually consist of assessing and addressing environmental impacts, impacts to other users of the area, and impacts to the electrical grid.

SR5.1 Be environmentally acceptable

The WEC farm technology and design shall enable the construction of a power farm that meets all environmental regulations. Thus, it shall cause no unacceptable impacts on the seafloor, no unacceptable impacts on local currents or sedimentation, no unacceptable impacts on local or global wildlife, and no unacceptable impacts on local or global marine life.

SR5.2 Be acceptable to other users of the area

The WEC farm technology and design must integrate smoothly with other users of the area. Other users of the area are local and global fishing industries, other industries using the local area, recreational users of the local area, tourists and entertainment users of the local area, and local communities. 
The WEC farm shall deliver electrical power that meets grid operator requirements for power quality, including voltage, frequency, and flicker.

\subsection{Safety}

Safety is a critical concern as soon as human activities are involved. For the WEC farm, the stakeholders most directly concerned are the WEC subsystem designer, WEC subsystem manufacturers, the WEC farm construction company, the WEC farm operator, marine contractors, and maintenance service providers. Investors are indirectly concerned because they want to maintain good reputations to ensure future market share. The stakeholder requirement is:

\section{SR6. Be safe}

Safety is a key requirement as soon as human activities are involved, particularly at sea. The WEC power farm shall be safe at each stage of its lifecycle. The focus shall be on the construction, operations, and disposal stages.

\subsection{Market size}

To ensure a sustainable business, the WEC farm developer's ability to provide steady sales is a key requirement for the WEC farm construction company, and for industries in the supply chain. It may also be an important requirement for the local, regional, and national development agencies, policymakers, and general public to know that the WEC farm business is replicable, sustainable, and large enough to warrant policy, agency, and public support. Thus, the WEC farm shall be deployable at many different sites that represent a large national and global market share:

\section{SR7. Be deployable globally}

The ability to provide steady sales is another key requirement for sustainable business for the WEC farm developer, the WEC farm construction company, and for the suppliers of the supply chain. It may also be an important requirement for the local, regional, and national development agencies, policymakers, and general society with respect to the overall benefits from the WEC farm. Thus, the WEC farm shall be deployable at many different sites that represent a large national and global market share. It shall be able to adapt to variable site characteristics, including wave resource, geophysical conditions, distance to shore, and local infrastructure.

\section{DISCUSSION AND CONCLUSIONS}

Analysis of stakeholders' needs leads to the specification of seven high-level stakeholder requirements. Five of these have been split into sublevel requirements. Some of the sublevel requirements have been split into sub-sublevel requirements. Satisfaction of a requirement at a higher level depends on the satisfaction of the requirement at the sublevel. For example, satisfaction of the low CapEx requirement (S0) depends on the satisfaction of lower-level requirements such as S0, Design for low cost; S0, Manufacture at low cost; S0, Be inexpensive to transport; and S0, Be inexpensive to install. Thus, one should focus first on the lower-level requirements when assessing the performance of a particular WEC farm with respect to stakeholders' needs. 
Wave energy farm: The wave energy farm will convert ocean wave energy to electricity and deliver it to the continential grid market in a competitive and acceptable manner across the lifecycle

\begin{tabular}{|c|c|c|}
\hline $\begin{array}{l}\text { SR1. } \\
\text { Have market- } \\
\text { competitive } \\
\text { cost of energy }\end{array}$ & $\begin{array}{c}\text { SR2. } \\
\text { Provide a secure } \\
\text { investment } \\
\text { opportunity }\end{array}$ & $\begin{array}{l}\text { SR3. } \\
\text { Be reliable } \\
\text { for grid } \\
\text { operations }\end{array}$ \\
\hline $\begin{array}{l}\text { SR1.1 Have as low } \\
\text { CapEx as possible }\end{array}$ & \multirow{2}{*}{$\begin{array}{l}\text { SR2.1 Provide low } \\
\text { uncertainly on cost } \\
\text { and revenues }\end{array}$} & \multirow{4}{*}{$\begin{array}{l}\begin{array}{l}\text { SR3.1 Be } \\
\text { forecastable }\end{array} \\
\begin{array}{l}\text { SR3.2 Have stable } \\
\text { annual power } \\
\text { production }\end{array}\end{array}$} \\
\hline SR1.1.1 Be a low- & & \\
\hline cost design & \multirow{2}{*}{$\begin{array}{l}\text { SR2.1.1 Provide } \\
\text { low uncertainly } \\
\text { on 0pEx }\end{array}$} & \\
\hline SR1.1.2 Be & & \\
\hline at a low cost & \multirow{2}{*}{$\begin{array}{l}\text { SR2.1.2 Provide } \\
\text { low uncertainly } \\
\text { on availability }\end{array}$} & \multirow[b]{2}{*}{$\begin{array}{l}\text { SR3.3 Be useful } \\
\text { to the grid }\end{array}$} \\
\hline SR1.1.3 Be & & \\
\hline $\begin{array}{l}\text { transport } \\
\text { to }\end{array}$ & \multirow{2}{*}{$\begin{array}{l}\text { SR2.1.3 Provide } \\
\text { low uncertainly on } \\
\text { energy production }\end{array}$} & \\
\hline \multirow{2}{*}{$\begin{array}{l}\text { SR1.1.4 Be } \\
\text { inexpensive to } \\
\text { install }\end{array}$} & & \\
\hline & \multirow{2}{*}{$\begin{array}{l}\text { SR2.1.4 Provide } \\
\text { low uncertainly } \\
\text { on CapEx }\end{array}$} & \\
\hline $\begin{array}{l}\text { SR1.2 Have as low } \\
\text { OpEx as possible }\end{array}$ & & \\
\hline SR1.2.1 Be reliable & \multirow{2}{*}{\begin{tabular}{|l|l|} 
SR2.2 Be survivable \\
$\begin{array}{l}\text { SR2.2.1 Be able to } \\
\text { survive extreme } \\
\text { loads/responses }\end{array}$ \\
\end{tabular}} & \\
\hline SR1.2.2 Be durable & & \\
\hline $\begin{array}{l}\text { SR1.3 Generate large } \\
\text { amounts of electricity }\end{array}$ & \multirow{2}{*}{\begin{tabular}{|l|} 
SR2.2.2 Be able to \\
cope with grid \\
failures or grid loss \\
\end{tabular}} & \\
\hline \multirow{2}{*}{$\begin{array}{l}\text { SR1.3.1 Absorb } \\
\text { large amounts of } \\
\text { wave energy }\end{array}$} & & \\
\hline & \multirow{2}{*}{$\begin{array}{l}\text { SR2.2.3 Be able to } \\
\text { avoid and survive } \\
\text { two collisions }\end{array}$} & \\
\hline \multirow{2}{*}{$\begin{array}{l}\text { SR1.3.2 Have high } \\
\text { energy conversion } \\
\text { efficiency }\end{array}$} & & \\
\hline & \multirow{2}{*}{$\begin{array}{l}\text { SR2.2.4 Be } \\
\text { survivable in } \\
\text { temporary } \\
\text { conditions } \\
\end{array}$} & \\
\hline $\begin{array}{l}\text { SR1.4 Have high } \\
\text { availability }\end{array}$ & & \\
\hline SR1.4.1 Be reliable & & \\
\hline SR1.4.2 Be durable & & \\
\hline $\begin{array}{l}\text { SR1.5 Have a low } \\
\text { financing rate }\end{array}$ & & \\
\hline $\begin{array}{l}\text { SR1. } 6 \text { Have a low } \\
\text { insurance rate }\end{array}$ & & \\
\hline
\end{tabular}

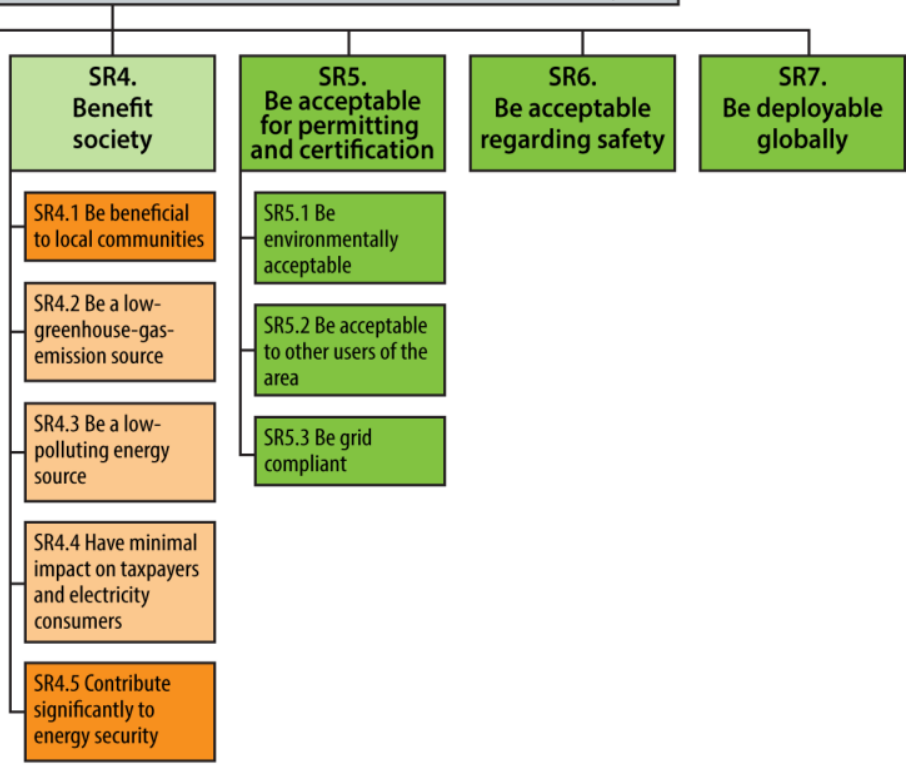

No flexibility: a wave energy converter (WEC) farm must satisfy this requirement to be viable

Some flexibility: a WEC farm may not satisfy this requirement but will trade off with another requirement to make the higher level requirement viable

Medium flexibility: a WEC farm may only partly satisfy this requirement and still be viable

High flexibility: a WEC farm may not satisfy this requirement and still be viable.

\section{Figure 4. Stakeholder requirements for a commercially successful WEC farm (Illustration by Alfred Hicks, NREL)}

Figure 4 shows 33 requirements to consider at the lower levels. However, the most important requirements are the seven at the highest level. Assessing the performance of the WEC farm at the sublevels is only a necessary step to enable assessment of the performance of the WEC farm with respect to stakeholders' requirements at the highest level.

It must be acknowledged that most requirements are flexible. For example, a technical solution may not fully satisfy one particular requirement, but trade-off with another requirement may make the higherlevel requirement viable. Also, not all stakeholders are equally important; thus, a technical solution may not satisfy a requirement of a lower-importance stakeholder and still be viable. Four degrees of flexibility have been identified:

- No flexibility - any WEC farm must satisfy this requirement to be viable

- Some flexibility - a WEC farm may not fully satisfy this requirement but will trade-off with another requirement to make the requirement at the higher level viable

- Medium flexibility — a WEC farm may only partly satisfy this requirement and still be viable 
It is believed that the present list comprehensively captures the requirements for a WEC farm to successfully accomplish its mission (i.e., convert wave energy to electricity and deliver it to the continental grid market in a competitive and acceptable manner across the lifecycle). Indeed, all identified needs and desires of all identified stakeholders of the WEC farm in all the identified stages of the lifecycle are captured by at least one of the requirements in the list. Therefore, this work is expected to be helpful for new WEC technology developers because it provides guidance and objectives for the design process. Existing WEC technology developers may already have developed their own lists of requirements that may have different structures and specifications. It must be acknowledged that these lists should be equally satisfactory provided that all stakeholders' needs in Tables 1 to 4 are captured.

Historically, WEC technology value has largely been measured by technology readiness and TRLs. Deficiencies with this approach were analyzed in [1] and [2]. The need for a measure identifying market viability was highlighted, and the concept of TPLs was introduced. It is now widely acknowledged in the wave energy industry that both technology readiness (TRL) and economic viability (TPL) needs to be taken into account to assess the value of a WEC technology.

It is believed that the list of requirements that have been developed in this work should serve as the components of the TPL metric. The TPL score could be used by investors and funding agencies to make informed decisions when allocating resources to wave energy technology developers. The TPL metric could also be used to perform benchmarking studies between different WEC technologies. Such studies would be much more comprehensive than other recent studies such as [13], [14], [15], [16], and [17] that essentially used proxies for cost of energy or energy performance. In the long term, it is believed that using a TPL metric based on the present or improved list of stakeholder requirements may prove helpful toward WEC technology convergence.

Nevertheless, assessing precisely to what extent a given technology satisfies the requirements may prove to be difficult in the early TRL stages. It may require detailed technical information that may become available only at a later TRL stage. However, the Pareto principle may apply for most of the requirements, and it may be possible to develop simplified methodologies for the early TRLs that could capture, for example, $80 \%$ of the technology performance with $20 \%$ of resources needed for the precise assessment. Future work may be carried out in this direction. Also, the focus of this paper was on the continental grid market. Stakeholders' requirements may need to be updated for other markets (desalination or nongrid-connected users).

\section{ACKNOWLEDGEMENTS}

This work was supported by the U.S. Department of Energy under Contract No. DE-AC3608GO28308 with the National Renewable Energy Laboratory. Funding for the work was provided by the DOE Office of Energy Efficiency and Renewable Energy, Wind and Water Power Technologies Office. Sandia National Laboratories is a multiprogram laboratory managed and operated by Sandia Corporation, a wholly owned subsidiary of Lockheed Martin Corporation, for the U.S. Department of Energy's National Nuclear Security Administration under contract DE-AC04-94AL85000.

The U.S. Government retains and the publisher, by accepting the article for publication, acknowledges that the U.S. Government retains a nonexclusive, paid-up, irrevocable, worldwide license to publish or reproduce the published form for this work, or allow others to do so, for U.S. Government purposes.

\section{REFERENCES}

[1] Weber, J.W., 2012 "WEC technology readiness and performance matrix - finding the best research development trajectory," in Proc. of the $4^{\text {th }}$ International Conference on Ocean Energy (ICOE2012), Dublin, Ireland. 
[2] Weber, J.W.; Costello, R.; Ringwood, J., 2013, "WEC Technology Performance Levels (TPLs) metric for successful development of economic WEC technology," in Proc. of the $10^{\text {th }}$ European Wave and Tidal Energy Conference (EWTEC2013), Aalborg, Denmark.

[3] Weber, J.W.; Laird D., 2015, "Structured Innovation of High-Performance Wave Energy Converter Technology," in Proc. of the $11^{\text {th }}$ European Wave and Tidal Energy Conference (EWTEC2015), Nantes, France

[4] http://waveenergyprize.org/ Accessed on June 20, 2016.

[5] International Standards Organization, ISO/IEC/IEEE 15288:2015, "Systems engineering-System lifecycle processes."

[6] Harris, R.E.; Johanning, L.; Wolfram, J., 2004, "Mooring systems for wave energy converters: a review of design issues and choices," in Proc. of the $3^{\text {rd }}$ International Conference on Marine Renewable Energy.

[7] Tande, J.O.; Di Marzio, G.; Uhlen, K., 2007, "System requirements for wind power plants," Technical report, SINTEF Energy research, Norway.

[8] IEEE 1233 “Guide for Developing System Requirements Specifications.” Institute of Electrical and Electronics Engineers (http://www.standards.ieee.org/).

[9] Faulconbridge, R.I.; Ryan, M.J. "Systems Engineering Practice," Argos Press, Canberra, 2014.

[10] Davies, P.A., 2006, "Wave-power desalination: resource assessment and review of technology," Desalination Vol. 186, pp. 97-109.

[11] Falcão, A.F.; De, O., 2009, "Wave energy utilization: a review of the technologies," Renewable and Sustainable Energy Reviews, Vol. 14, pp. 899-918.

[12] Carragher, P.; Hine, G.; Legh-Smith, P.; Mayville, J.; Nelson, R.; Pai, S.; Parnum, I.; Shone, P.; Smith, J.; Tichatschke, C.; 2013, "A new platform for offshore exploration and production," Oilfield review, Vol, 25(4).

[13] Meyer, N.I.; McDonald, Arnskov M.; Vad Bennetzen, L.C.E.; Burcharth, H.F.; Bunger J.; Jacobsen, V.; Maegaard, P.; Vindelov, S.; Nielsen, K.; Sorensen, J.N.; 2002, "Bølgekraftprogram: Afsluttende rapport fra Energistyrelsens Rådgivende," Rambøll, Teknikerbyen 31, 2830 Virum, Denmark: Bølgekraftudval Bølgekraftudvalgets Sekretariat. In Danish.

[14] Previsic, M.; Bedard, R.; Hagerman, G.; 2004, "E2I EPRI assessment: offshore wave energy conversion devices," E2I EPRI WP-004-US-Rev1, Electricity Innovation Institute.

[15] Babarit, A.; Hals, J.; Muliawan, M.J.; Kurniawan, A.; Moan, T.; Krokstad, J.; 2012, "Numerical benchmarking study of a selection of wave energy converters." Renewable Energy, Vol. 41, pp. 4463 [with Corrigendum in Renewable Energy, 2015, Vol. 74, pp. 955-957].

[16] Neary, V.; Previsic, M.; Jepsen, R.A.; Lawson, M.J.; Yu, Y.-H.; Copping, A.E.; Fontaine, A.A.; Hallet, K.C.; Murray, D.K.; 2014, "Methodology for design and economic analysis of marine energy conversion (MEC) technologies," Technical report from Sandia National Laboratories (USA), SAND2014e9040.

[17] Babarit, A., 2015, "A database of capture width ratio of wave energy converters," Renewable Energy, Vol. 80, pp. 610-628. 